\title{
Extraction of Human Genomic DNA from Dried Blood Spots and Hair Roots
}

\author{
Nguyen Thi Hue, Nguyen Dieu Hoai Chan, Phan Tuan Phong, Nguyen T. Thao. Linh, and Nguyen DT. \\ Giang
}

\begin{abstract}
In most studies about molecular genetics, molecular diagnostics, DNA extraction is considered as the very first step that will give a significant effective. The material used for DNA extraction is vary from fresh blood to dried blood, tissue, oral mucosa and hair root.... The dried blood and hair root are the two materials that easy to collect and can store for long term, which leads to more advantages for many time extractions to have fresh DNA and enough amount DNA for further studies. This study introduces an efficient phenol method with 2 steps of lyses which allows high yield of DNA concentration from dried blood and hair root. Comparing to the commercial QIAamp ${ }^{\circledR}$ DNA Mini Kit which applied for dried blood sample, DNA concentration extracted from this method was higher, the quality of DNA was equal and the cost is lower. Comparing to salting out method, a cheap and safe method, which an applied for hair root, the two-step lysis phenolic method also give higher efficiency. This method could be the useful tool which may apply for further molecular analysis studies using long storing time materials like dried blood spots and hair root samples.
\end{abstract}

Index Terms-Efficient PCR assay, dried blood spot, DNA extraction, hair roots.

\section{INTRODUCTION}

The reliability and performance of the molecular diagnostic assays which are polymerase chain reaction (PCR), enzyme digestion and recombinant selection [1] are strongly influenced by the extraction of input material, in this case, the quantity and quality of nucleic acids from clinical samples. Although blood is highly recommended for DNA extraction, for the experiments in the extremely hard working environment, blood may be difficult to be stored in long term. Furthermore the ease of collecting, costs of transporting, costs of storing and pre-processing should be taken all into consideration how to get an optimal choice of samples. Then despite of blood is the most commonly used sample since it provides enough and high quality DNA, people look for other sources which are low cost, easy to collect and convenient to store.

Dried blood is recommended for well storing request that is collected on filter paper for history of more than 40 years

Manuscript received November 30, 2011. This work was supported in part by the National Foundation for Science and Technology Development, V.N., and Vietnam National University HCMC.

Nguyen Thi Hue is with the Biotechnology Department, School of Biotechnology, International University, VNU, HCMC, Vietnam (Phone: +84-983886884; Fax: +84-8-3724-4271; e-mail: nthue@hcmiu.edu.vn).

Nguyen Dieu Hoai Chan and Phan Tuan Phong are with Department of Biotechnology, School of Biotechnology, International University, VNU, HCMC, Vietnam (e-mail: ndhchan@hcmiu.edu.vn, squiral86@yahoo.com).
[2]. A wide application from diagnostic screening [2], drug monitoring [3], and genetic analysis [4], especially molecular epidemiologic studies in remote areas, where transport and storage conditions are not optimal, is proving the practicable and convenient property of this kind of material. Particularly for new born blood samples, which are needed for new born screening program of inherited diseases, a few drops from heel is absorbed into special filter paper [5]. However, a crucial problem of dried blood spot material is the limitation of the blood amount that could be incorporated into one extraction assay. Therefore, an efficient method for genomic DNA extraction which preserves the integrity, offers the purity, stability, and utilize all the limited amount of sample is highly required. There are several methods were recommend for DNA extraction from dried blood spots, e.g., Sumonta Chaisomchit et al. [6] introduced a method used buffered phenol as a solvent to separate DNA from protein and cell debris. Phenol extraction is a commonly used method for removing proteins from a DNA sample, e.g. to remove proteins from cell lysate during genomic DNA preparation[7]. During organic extraction, protein contaminants are denatured and partition either with the organic phase or at the interface between organic and aqueous phase, while nucleic acids remain in the aqueous phase. Proteinase $\mathrm{K}$ is commonly used in molecular biology to digest protein and remove contamination from preparations of nucleic acid. It also could be applied widely in most cases of DNA extraction such as genomic DNA isolation from tissue[8], DNA extraction from blood, or DNA isolation of bone. However, a large amount of Proteinase $\mathrm{K}$ must be used and the success belongs to the commercial Buffered Phenol (USB Corporation, OH, USA) [6] that results high cost whereas the DNA amount is not constantly high. Another method was commercialized to QIAamp® DNA Mini Kit which yields 1000ng of DNA per assay. However, high cost due to large amount using of Proteinase $\mathrm{K}$ and Phenol, spin column is always the trouble for research. Moreover, the spin column kits always result in increased plastic waste. Then this study was performed to come up with an optimal method for convenient use with lower cost and higher DNA concentration as well as higher purity of DNA compared to QIAamp® DNA Mini Kit.

For the later part of this study, another material source, hair roots, was applied to try to widen the working region of this method. Hair root is the preferred sample for genetic testing because it the most easy sample-kind to collect. However, since hair roots contain extremely small amount of DNA $[9,10]$, it is quire hard to yield enough amount of DNA with high quality which is important for conducting PCR and sequencing reactions [11]. Fortunately, phenol and 
salting-out method was proved the suitable treatment for DNA from hair roots [12]. Salting out is a method of separating proteins based on the principle that proteins are less soluble at high salt concentrations [12]. Furthermore, the phenol method and salting-out method take low cost than others, therefore they can be applied in various laboratories [12]. Then we applied this study's method on hair roots with different groups with different storing time, compared to salting-out method, to identify the most suitable storage time of hair roots sample and evaluate how our method give high quality and quantity of DNA.

\section{MAterials AND MEthODS}

\section{A. Subjects}

194 dried blood spots samples were collected from $\mathrm{Tu} \mathrm{Du}$ Hospital (Ho Chi Minh City - Vietnam) in the new born screening program. Blood from baby heels is absorbed into 903-SandS filter paper card with at least one spot with diameter of $1 \mathrm{~cm}$.

Hair roots were collected from 20 volunteers, who had not treated their hair with any chemicals for hairdressing, straightening, and dyeing[13]. The total amount of samples was 200 hair roots (i.e., 10roots/person) and divided into two groups equally. Group 1 was represented for fresh hair roots and the other was for samples stored in one week.

\section{B. Optimization of One Step and Two-Steps Lysis Phenolic Method in Dried Blood Spots}

Forty four dried blood spots samples were used. 3 circles of $3 \mathrm{~mm}$ diameter of blood spots were used for each assay, after that they were treated with lysis buffer, Proteinase K, fresh buffered-Phenol: Chloroform: Isoamylalcohol (25: 24:1). Phenol solution was prepared from crystal Phenol and must be saturated for 1 week before use.

The One-step Lysis method was set up for six assays that varied the amount of Lysis Buffer I and Proteinase K, each assay was performed in triplicate. This method was developed based on the Sumota Chaisomchit method [6]. Lysis buffer I included Tris $\mathrm{HCl} 10 \mathrm{mM}, \mathrm{MgCl}_{2} 5 \mathrm{mM}$, Triton X100(1\%v/v), SDS $1 \% \mathrm{w} / \mathrm{v}$, EDTA $10 \mathrm{mM}$, and was adjusted with $\mathrm{pH} 8.0$, was used for assay in two group of volume $200 \mu \mathrm{l}$ and $300 \mu \mathrm{l}$. The Proteinase $\mathrm{K}$ was used for assays in varied amount from $0.01,0.02$, to $0.03 \mathrm{mg}$ (Table I).

Three circles of dried blood spot were vortex with Lysis buffer I for $30 \mathrm{~s}$, incubated at $85{ }^{\circ} \mathrm{C}$ for $20 \mathrm{~min}$. The lysates were cooled down at room temperature for $10 \mathrm{~min}$, added Proteinase K, vortex for $30 \mathrm{~s}$, and incubated at $65^{\circ} \mathrm{C}$ in $1 \mathrm{hr}$. Add the same amount of buffer phenol: chloroform: izoamylalcohol $(25: 24: 1)$ into those samples, then mixed well.

TABLE I: ONE-STEP LYSIS ASSAY SET UP

\begin{tabular}{|lcccccc|}
\hline \multicolumn{1}{|c}{ Assay } & $\mathbf{1}$ & $\mathbf{2}$ & $\mathbf{3}$ & $\mathbf{4}$ & $\mathbf{5}$ & $\mathbf{6}$ \\
\hline $\begin{array}{l}\text { Lysis } \\
\text { buffer }(\boldsymbol{\mu l})\end{array}$ & 200 & 200 & 200 & 300 & 300 & 300 \\
$\begin{array}{l}\text { Proteinase } \\
\text { K (mg) }\end{array}$ & 0.01 & 0.02 & 0.03 & 0.01 & 0.02 & 0.03 \\
\hline
\end{tabular}

TABLE II: TWO-STEP LYSIS ASSAY SET UP

\begin{tabular}{|lccc|}
\hline Assay & $\mathbf{7}$ & $\mathbf{8}$ & $\mathbf{9}$ \\
\hline Lysis buffer I $(\boldsymbol{\mu l})$ & 100 & 150 & 200 \\
Lysis buffer II $(\boldsymbol{\mu l})$ & 100 & 100 & 100 \\
Proteinase K $(\mathbf{m g})$ & 0.01 & 0.01 & 0.01 \\
\hline
\end{tabular}

For $30 \mathrm{~s}$, After centrifugation at $10,000 \mathrm{rpm}$ for $4 \mathrm{~min}$ at room temperature, the upper phase were taken out and treated with Sodium Acetate (3M, pH 5.2), and Iso-Propanol. Then the samples were washed by Ethanol $70 \%$ and DNA was collected by elution with $50 \mu \mathrm{l} \mathrm{dH}_{2} \mathrm{O}$.

The two-steps lysis method is differed from the one-step method by adding one more step of cell lysis. The lysis buffer II was used for the second step lysis in combination with first lysis with lysis buffer I. Lysis Buffer II included TrisHCl $30 \mathrm{mM}$, EDTA $20 \mathrm{mM}$, SDS $3 \%$, and was adjusted with $\mathrm{pH}$ 8.0. The second step of lysis was applied after degrading proteins by proteinase $\mathrm{K}$. This experiment was examined 3 assays with varied Lysis Buffer I and proteinase K. Each assay was performed in triplicates (Table II).

\section{Appling Phenolic Method for Dried Blood Spots in Comparison with Commercial Kit.}

150 dried blood spots samples were extracted by the optimal protocol, and 17 samples were extracted by QIAamp ${ }^{\circledR}$ DNA Mini Kit. The average DNA concentration and purity was compared. A PCR assay was performed to evaluate the quality of

\section{Appling the Phenolic Two-Step Lyses Method for Hair} Roots in Comparison with Salting-Out Method

The Phenolic Two-step lyses method was the optimal one from the previous experiment. The extraction protocols of these two method, phenol and salting-out based, were almost identical except for in salting-out method, phenol: chloroform: isoamylalcohol (25:24:1) step was not applied. Each assay was contained 5 hair roots, and treated with Phenolic Two-step lyses method or Salting-out method.

\section{E. Evaluation Method for DNA Solution}

The NanoDrop Spectrophotometer ND-1000 was used to measure the concentration and purity of the DNA solution. DNA absorbs UV light in a specific pattern. In a spectrophotometer, a sample is exposed to UV light at 260 $\mathrm{nm}$, and a photo-detector measures the light that passes through the sample. The more light absorbed by the sample, the higher the nucleic acid concentration in the sample [14]. The good DNA concentration is expected higher than $50 \mathrm{ng} / \mathrm{ul}$, and the good purity is expected in the the range 1.7 -1.9 (A260nm/A280nm)

$10 \mu \mathrm{l}$ of extracted DNA solution is checked by electrophoresis with $0.7 \%$ agarose gel to estimate the purity and may concentration of DNA.

Furthermore a PCR assay was performed using the extracted DNA to evaluate the quality of DNA solution based on the ability to be amplified presented by the PCR product or the band on agarose gel. The set of two primers G6PD-E2-F

5'-CTCAAGAAAGGGGCTAACTTCTCAA-3' and G6PD-E2-R 5'-GCACTTCCTGGCTTTTAAGATTGGG-3' 
was used to qualify the DNA from dried blood spots. The set of two primers $\mathrm{HGH1}$ 5' GCCTTCCCAACCATTCCCTTA-3' and HGH2 5'CAAGGATTTCTGTTGTGTTTC-3' was used to quality DNA extracted from hair roots. The G6PD primer set will give PCR product at $241 \mathrm{bp}$ and the $\mathrm{HGH}$ primer set will give the PCR product at $496 \mathrm{bp}$ on agarose gel.

The PCR assays were carried out by using QIAGEN TopTaq Master Mix Kit with $0.5 \mu \mathrm{M}$ of each primer and 40ng of DNA in the total volume of $25 \mu 1$. The results were analysed by gel electrophoresis with $1.5 \%$ agarose gel.

\section{RESULTS}

\section{A. Evaluation of the Phenolic Two-Step Lyses Method with One-Step Lyses Method, and Commercial Kit}

Comparing the concentration and purity of DNA solution which extracted by one-step, two-step lysis method and Qiagen Kit, the result show that there was no sample giving the DNA concentration more than $50 \mathrm{ng} / \mu \mathrm{l}$ in one-step method. Assay 2 achieved the best result when it came up with $100 \%$ samples had DNA concentration in the range from $20-50 \mathrm{ng} / \mu \mathrm{l}$, and the purity is 1.7 , which were in the range of highly pure DNA (1.7 to 1.9$)$. The two others assays 1 and 4 were not quite good when they just had $33.33 \%$ samples yielded more than $20 \mathrm{ng} / \mu 1$, and their purity were less than 1.7, that were 1.61 and 1.56. The others assays were gave the DNA concentration too low $<20 \mathrm{ng} / \mu \mathrm{l}$, and their purity value showed lower the range (see Table III).

The data of DNA extracted from the Two-step lysis method is showed in the Table IV. 100\% samples of assay 9 yielded the concentration of DNA were more than $50 \mathrm{ng} / \mu 1$. That is a very good result even the purity of DNA in this assay is 1.65 out the range of good purity but not much. Assay 7 and 8 were not much worse than assay 9 since all samples gave the high yield, from $20 \mathrm{ng} / \mu \mathrm{l}$ to $50 \mathrm{ng} / \mu \mathrm{l}$. However, the DNA purity is drop down to 1.55 (see Table IV).

In overall the two-step lysis seems better than one-step lysis method. When comparing the average DNA concentration and purity of all samples which extracted by two methods, the result showed that the better one is the two-step lysis method when they gave the higher DNA concentration $51.9 \mathrm{ng} / \mathrm{ul}$ compare to $17.6 \mathrm{ng} / \mathrm{ul}$ in one-step method, although the purity is a bit lower (Table V). The assay 9 is the best one within assays in the two-step lysis method. Assay 9 was used to compare with QIAamp ${ }^{\circledR}$ DNA Mini Kit.

TABLE IIII: CONCENTRATIONS OF EXTRACTED DNA BY ONE-STEP LYSIS

\begin{tabular}{|l|c|c|c|c|c|c|}
\multicolumn{7}{c|}{ METHOD } \\
\hline \multirow{2}{*}{$\begin{array}{c}\text { Concentration } \\
(\mathbf{n g} / \boldsymbol{\mu l})\end{array}$} & $\mathbf{1}$ & $\mathbf{2}$ & $\mathbf{3}$ & $\mathbf{4}$ & $\mathbf{5}$ & $\mathbf{6}$ \\
\cline { 2 - 8 } & 0 & 0 & 0 & 0 & 0 & 0 \\
$20-50$ & 33.33 & 100 & 0 & 33.33 & 0 & 0 \\
$<20$ & 66.67 & 0 & 100 & 66.67 & 100 & 100 \\
\hline Purity & 1.61 & 1.7 & 1.96 & 1.56 & 1.58 & 1.52 \\
\hline
\end{tabular}

TABLE IV: CONCENTRATIONS OF EXTRACTED DNA BY TWO-STEP LYSIS METHOD

\begin{tabular}{|l|c|c|c|}
\hline \multirow{2}{*}{ Concentration $(\mathrm{ng} / \boldsymbol{\mu l})$} & \multicolumn{3}{|c|}{ Assay (\%) } \\
\cline { 2 - 4 } & $\mathbf{7}$ & $\mathbf{8}$ & $\mathbf{9}$ \\
\hline$>50$ & 0 & 0 & 100 \\
$20-50$ & 100 & 100 & 0 \\
$<20$ & 0 & 0 & 0 \\
\hline Purity & 1.55 & 1.55 & 1.65 \\
\hline
\end{tabular}

TABLE V: COMPARISON OF DNA CONCENTRATION EXTRACTED BY DIFFERENT METHODS

\begin{tabular}{|l|c|c|}
\hline \multirow{2}{*}{ Quality } & $\begin{array}{c}\text { Extraction } \\
\text { Method }\end{array}$ & \\
\cline { 2 - 3 } & One step & Two step \\
\hline Concentration $(\mathbf{n g} / \boldsymbol{\mu l})$ & 17.6 & 51.9 \\
Purity & 1.66 & 1.58 \\
\hline
\end{tabular}

TABLE VI: COMPARISON BETWEEN OPTIMAL PROTOCOL AND COMMERCIAL KIT

\begin{tabular}{|l|c|c|}
\hline \multirow{2}{*}{ Concentration (ng/ $\boldsymbol{\mu l})$} & \multicolumn{2}{|c|}{ Method (\%) } \\
\cline { 2 - 3 } & Assay 9 & QIAgen KIT \\
N=150 & 0 \\
\hline$>50$ & 10.7 & 0 \\
$20-50$ & 29.3 & 100 \\
$<20$ & 60 & 7.7 \\
Average Conc. & 25.68 & 1.8 \\
\hline Average Purity & 1.5 & 17 \\
\hline
\end{tabular}

150 samples were examined using assay 9 and 17 samples were examined using commercial kit. Assay 9 was seen better than QIAamp® DNA Mini Kit with $10.7 \%$ of samples gave DNA concentration higer than $50 \mathrm{ng} / \mu \mathrm{l}$, and $29.3 \%$ of samples gave concentration in the range $20 \mathrm{ng} / \mu \mathrm{l}$ to $50 \mathrm{ng} / \mu \mathrm{l}$ whereas $100 \%$ of samples of QIAamp ${ }^{\circledR}$ DNA Mini Kit gave low yield DNA $(<20 \mathrm{ng} / \mu \mathrm{l})$. Comparing the average DNA concentration of all samples, the assay 9 showed much better result compare to QIAamp ${ }^{\circledR}$ DNA Mini Kit. $25.68 \mathrm{ng} / \mu \mathrm{l}$ is the average DNA concentration of samples extracted by assay 9 while $7.7 \mathrm{ng} / \mu \mathrm{l}$ is that by QIAamp® DNA Mini Kit (Table VI). However, the commercial kit gave higher purity value (1.8) which was quite low (1.5) in assay 9.

In order to evaluate the DNA solution which will be used for further molecular analysis studies, the successful in PCR assay is one of criteria. Approximate 40ng of DNA was used for a PCR assay. PCR assays were performed for some randomly selected DNA extracted samples. The result showed that with the same amount of DNA, all samples yielded from two-step lysis method gave PCR products as well as the one from DNA extracted by QIAamp ${ }^{\circledR}$ DNA Mini Kit. The DNA extracted by one-step lysis method gave no PCR product. It could be with low concentration the volume of DNA extracted applied for the PCR need to be bigger which leads to high concentration of contaminants compared to others samples with higher DNA concentration. Thus contaminants affect the PCR results (Fig. 1).

The extracted DNA from two-step lysis method and commercial Kit were stored in two months in the same 
condition, at $4^{0} \mathrm{C}$ and applied in PCR assay. The good PCR results were seen all samples from both methods (Fig.2). This indicated that the two-step lysis method, particularly the assay 9 can achieve with the high quality and quantity of DNA in comparing with QIAamp ${ }^{\circledR}$ DNA Mini Kit.

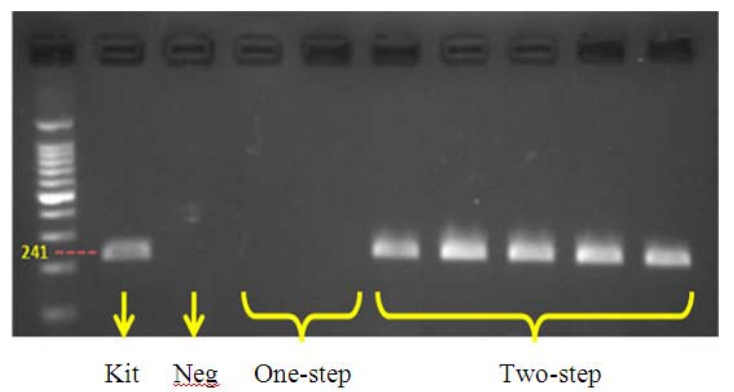

Fig. 1. Checking quality of DNA by PCR assay, lane 1: DNA extracted by Qiagen KIT, lane 2: negative control with water as template, lane 3, 4: DNA extracted by one step lysis protocol

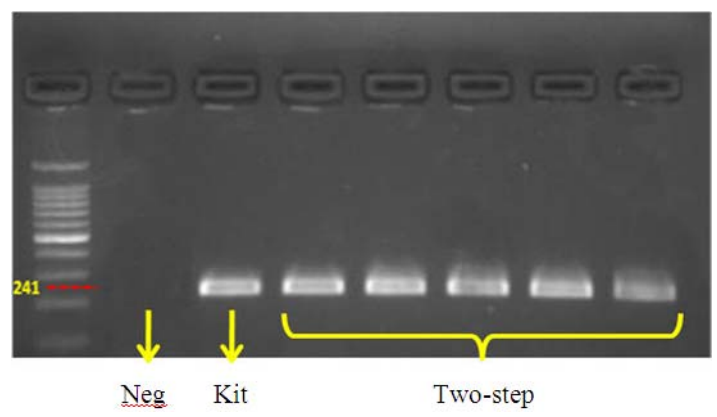

Fig. 2. Checking DNA sample after 2 months stored by PCR assay, PCR product at $241 \mathrm{bp}$ is the right product, lane 1: negative control with water as template, lane 2: DNA sample extracted by Qiagen KIT, lane 3, 4, 5, 6, 7: DNA samples extracted by assay 9 .

\section{B. Applying Two-Step Lysis Method in Hair Roots in Comparison with Salting-Out Method}

The salting out method can be applied for extraction of DNA from several materials with low cost and safer as phenol is not required. With the hair root, one of materials which easy to collect but may yield little DNA, the optimal two-step lysis method and the salting out method were applied to evaluate the suitable method which can applied for hair root material.

With fresh hair root material, the phenolic method achieved with higher DNA concentration and higher purity compare to salting out method. Average DNA concentration achieved in phenolic method is $87 \mathrm{ng} / \mu \mathrm{l}$ and purity is 1.7 while those are $42 \mathrm{ng} / \mu \mathrm{l}$ and 1 respectively, in salting out method (Table VII). The same result was seen in the one-week stored hair root samples with $17 \mathrm{ng} / \mathrm{ul}$ compared to $8 \mathrm{ng} / \mathrm{ul}$ in concentration and 1.7 compare to 1 in purity value (table VII). When comparing the DNA extracted from fresh hair root and 1 week-stored hair root, the result from fresh hair root samples is better than stored hair roots samples with the higher DNA concentration $87 \mathrm{ng} / \mathrm{ul}$ in fresh hair roots compared to $17 \mathrm{ng} / \mathrm{ul}$ in stored hair roots in phenolic method (table VII). The result is the same in salting out method with $42 \mathrm{ng} / \mathrm{ul}$ and $8 \mathrm{ng} / \mathrm{ul}$ respectively (Table VII). The good DNA solution was seen in phenolic method and better than in fresh hair roots with $60 \%$ of fresh hair root samples gave DNA concentration $>50 \mathrm{ng} / \mathrm{ul}$ while the stored hair roots gave lower range concentration and no sample gave concentration higher than 50ng/ul. However, the purity is good (1.7) is both sample sets (table VIII). In salting out method $30 \%$ fresh hair roots gave good DNA solution with concentration $>50 \mathrm{ng} / \mathrm{ul}$ while that is $0 \%$ in 1 week stored hair roots group. Most of stored hair root samples $(80 \%)$ gave very low concentration (table VIII).

For double checking, gel electrophoresis was applied for DNA solution which is extracted from two method and two stored time hair roots groups. With the fresh hair roots the DNA extracted by two methods showed the clear band of genomic DNA (Fig. 3-upper) while with the stored hair roots the phenolic method gave better result with all samples showed bands of genomic DNA while in salting out method some of sample gave no band (Fig. 3-lower).

TABLE VI: COMPARING AVERAGE CONCENTRATION AND PURITY OF DNA SOlution By EXTRACTION METHOdS AND STOREd Time OF HAir RoOTS.

\begin{tabular}{|l|c|c|c|c|}
\hline & \multicolumn{4}{c|}{ DNA solution } \\
\hline $\begin{array}{l}\text { Extraction } \\
\text { Method }\end{array}$ & \multicolumn{2}{|c|}{ Phenol } & \multicolumn{2}{c|}{ Salting - out } \\
\hline Hair root & Fresh & 1 week & Fresh & 1 week \\
\hline $\begin{array}{c}\text { Concentration } \\
(\text { ng/ } \mu \mathrm{l})\end{array}$ & 87 & 17 & 42 & 8 \\
Purity & 1.7 & 1.7 & 1 & 1 \\
\hline
\end{tabular}

TABLE VII: COMPARING CONCENTRATION RANGE OF DNA SOLUTION BY EXTRACTION METHOD AND STORED TIME HAIR ROOTS

\begin{tabular}{|c|c|c|c|c|}
\hline \multirow{2}{*}{ Method } & \multicolumn{4}{|c|}{ DNA solution } \\
\hline Hair roots & \multicolumn{3}{|c|}{ Phenol } & \multicolumn{2}{c|}{ Salting out } \\
\hline Conc (ng/ul) & Fresh & 1 week & Fresh & 1 week \\
\hline$>50$ & $60 \%$ & $0 \%$ & 30 & 0 \\
$20-50$ & $10 \%$ & $50 \%$ & 30 & 20 \\
$<20$ & $30 \%$ & $50 \%$ & 40 & 80 \\
\hline Purity & 1.7 & 1.7 & 1 & 1 \\
\hline
\end{tabular}
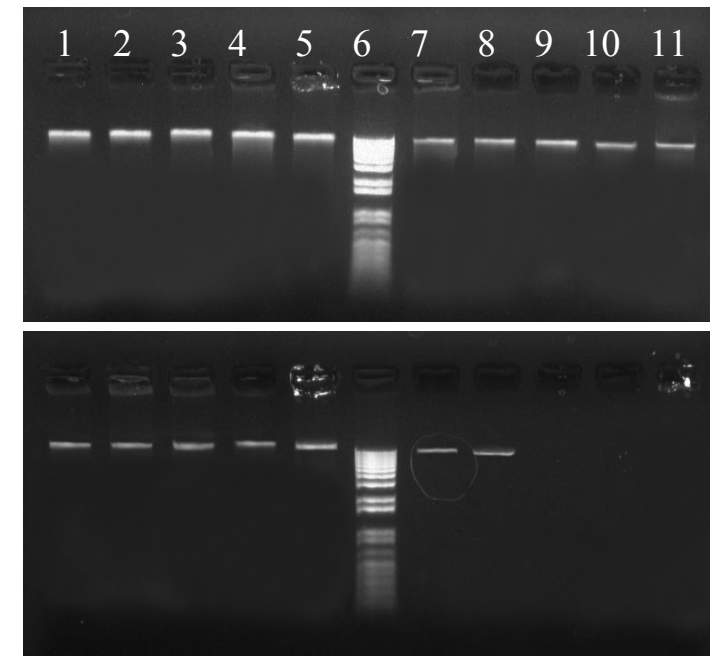

Fig. 3. Quality of genomic DNA is checked on $0.7 \%$ agarose gel. Fresh hair roots samples (Upper gel). One-week stored hair roots samples (lower gel). Phenolic method (Lane 1, 2, 3, 4, 5). Salting-out method (Lane 7, 8, 9, 10, 11). Lane 6: ladder $1 \mathrm{~kb}$ 


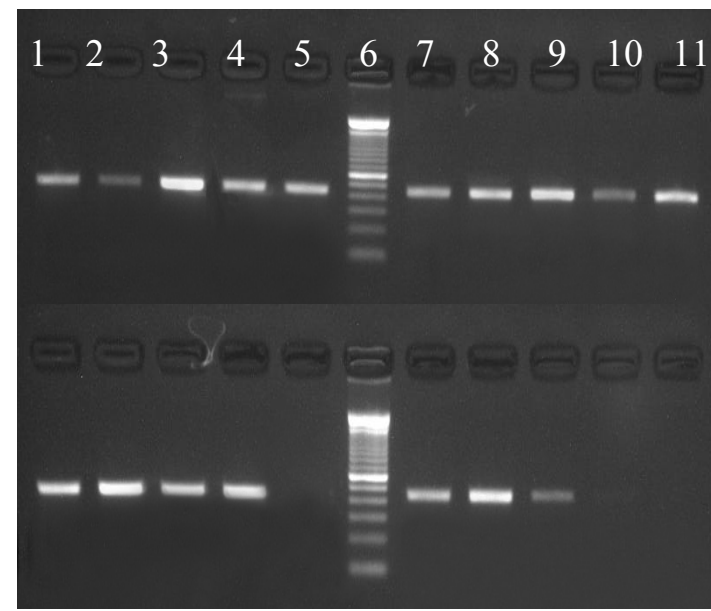

Fig. 4. Quality of extracted DNA is checked based on PCR products on $1.5 \%$ agarose gel. Fresh hair root geoup (upper gel). One week stored hair roots group (lower gel). Phenolic method (Lane 1, 2, 3, 4, 5). Salting-out method (Lane 7, 8, 9, 10, 11). Lane 6: ladder $100 \mathrm{bp}$

The quality of DNA solution was also checked by ability to be amplified through the PCR assay. All samples of fresh hair material gave good PCR products in either phenolic or salting out method whereas samples from the stored hair roots gave some failed PCR in even phenolic and salting out method. This could be due to the contaminant may too much in the PCR assay due to the large volume of DNA sample is required to get an adequate DNA amount for a PCR assay.

\section{DISCUSSION}

This study provides a simple, efficient method for extracting and purifying genomic DNA from dried blood and hair roots sample. We observed a high amount of genomic DNA when extracting by two-step lysis method. Since assay 9 gave best result which was purity and highest concentration of extracted DNA, it was selected to be final protocol for extraction of genomic DNA from dried blood spot on filter paper.

In comparison with Phenol One-step Lyses method and Salting-out method, the Two-step one is much dominant about both DNA concentration and DNA purity, which significantly affect the further PCR assays. In the extracting process, a number of chemicals such as phenol, salts, polyamines, polysaccharides are used that may still be contaminated with the DNA solution. These contaminants are considered as inhibitors for PCR assays $[15,16]$. Then with low DNA concentration extracted by One-step Lyses and Salting-out methods, the PCR assay may be on risk since a large volume of DNA solution would be used, that is, a large amount of contaminants or PCR inhibitors would be included. Thus the PCR assays are failed in producing PCR product as cannot see the bright bands on agarose gel.

One more lysis step is added into the extracting protocol aims to utilize all the cells inside filter paper. The impressive result of Two-step Lyses method indicates that the first lyses step may just release the cells away from paper and have not enough chemical or time to lyses the cells completely. That could be understand the second lyses step will finish the cell breaking and help to achieve more DNA.

When apply the two-step lysis phenolic method for hair root samples the result is very good as the chemical can affect directly to cells in the root of hair and breaking the cells to give out the DNA. It explains why the purity of DNA extracted from hair root is high why DNA extracted from dried blood spot on filter paper is lower.

In the comparison between Phenolic method and Salting-out method which apply in hair roots, the DNA yield of Phenolic method was significantly higher. The difference between 2 method is only applying Phenol: Chloroform: Isoamylalcohol (25:24:1) step in phenolic and not not apply this step in salting out method. It is clearly that the phenol step help to remove more unwanted proteins and precipitate DNA from the cell lysate. The phenol solution could be considered as the key factor of DNA extraction. In these experiments, a mixture of chloroform and phenol is often employed to maximize the yield of isolated DNA. The purity and $\mathrm{pH}$ of phenol solutions used in biochemical work is very important. The phenol solution needs to be stored in good conditions to avoid the oxidation of phenol.

When the result was observed by gel electrophoresis, there some of extracted DNA was smeared. This indicated that the extracted DNA was broken down during the extraction process. In phenol method, oxidized phenol can result in DNA damages and cannot be used. Ethanol precipitation of the DNA and subsequent ethanol washes eliminate such a contaminant; the chloroform reduces the amount of the DNA-containing aqueous layer at the phenol inter-phase. Similar to phenol, residual chloroform can be problematic, and should be removed by thorough drying. Drying is also employed to remove residual ethanol. Over dried DNA can be difficult to dissolve, so drying should be stopped shortly after the liquid can no longer be observed. Moreover, large DNA molecules can be easily sheared during extraction. Avoid vortexing, repeated pipetting (especially through low-volume pipette tips), and any other form of mechanical stress when the isolate is destined for applications that require high molecular weight DNA. Gentle manipulations may not always be possible during the isolation process. This usually does not cause damage to the secondary structure of the DNA, but it does reduce the length of the molecules.

Our method still dominates the competition with QIAamp ${ }^{\circledR}$ DNA Mini Kit that is two times higher in DNA concentration. Still, contamination cannot be avoided completely in phenolic method. However, the number 1.5 of purity can be an acceptable value when a small volume of DNA solution with high concentration for each PCR reaction is used that may overcome this obstacle.

In economic feature, the price to extracted DNA of one sample by our protocol is two times cheaper than using QIAamp® DNA Mini Kit (2.74\$ USD). Chaisomchit and colleagues (2003) have also presented a method for extracting DNA from dried blood. However, their method uses an amount of proteinase $\mathrm{K}$ eight times higher than our method, this leads to an increasing in the cost of their method. Besides, our home-made buffered phenol is an advance that helps much in cost reducing. For almost laboratories, this is the useful method to yield high concentration of DNA with acceptable purity and low cost. This optimal method can be applied for extraction of DNA from the difficult material such as hair roots and dried blood spots samples without difficulty. 


\section{ACKNOWLEDGMENT}

Thanks to volunteers from $\mathrm{Tu} \mathrm{Du}$ hospital - HCMC Vietnam who provided dried blood spots samples and volunteers from International University - VNU and Quang Nam Province hospital - Vietnam who provided hair roots samples for this study. Thanks to IU lab and OUCRU where instruments were used for this study.

\section{REFERENCES}

[1] T. Y. Wang et al., "A simplified universal genomic DNA extraction protocol suitable for PCR," Genet Mol Res, vol. 10, no. 1, pp. 519-525, 2011.

[2] R. Guthrie and A. Susi, "A Simple Phenylalanine Method for Detecting Phenylketonuria in Large Populations of Newborn Infants," Pediatrics, vol. 32, pp. 338-343, 1963.

[3] B. Lindstrom et al., "Determination of chloroquine and its desethyl metabolite in whole blood: an application for samples collected in capillary tubes and dried on filter paper," Ther Drug Monit, vol. 7, no. 2, pp. 207-210, 1985.

[4] T. W. Prior et al., "A model for molecular screening of newborns: simultaneous detection of Duchenne/Becker muscular dystrophies and cystic fibrosis," Clin Chem, vol. 36, no. 10, pp. 1756-1759, 1990.

[5] W. H. Hannon, R. J. Whitley, and B. Davin et al., Blood Collection on Filter Paper for Newborn Screening Programs, CLSI document, 2007.

[6] S. Chaisomchit et al., "A simple method for extraction and purification of genomic DNA from dried blood spots on filter paper," Southeast Asian J Trop Med Public Health, vol. 34, no. 3, pp. 641-645, 2003.
[7] D. K. Lahiri, A non-organic and non-enzymatic extraction method gives higher yields of genomic DNA from whole-blood samples than do nine other methods tested, J Biochem Biophys Methods, vol. 25, no. 4, pp.193-205, 1992.

[8] J. A. Ross, G. B. Nelson, and K. L. Holden, "DNA isolation from small tissue samples using salt and spermine," Nucleic Acids Res, vol. 19, no. 21, pp. 6053, 1991.

[9] R. Higuchi et al., "DNA typing from single hairs," Nature, vol. 332, no. 6164, pp. 543-546, 1988.

[10] B. Forslind and G. Swanbeck, "Keratin formation in the hair follicle. I. An ultranstructural investigation," Exp Cell Res, vol. 43, no.1, pp. 191-209, 1966.

[11] A. L. McOrist, M. Jackson, and A. R. Bird, "A comparison of five methods for extraction of bacterial DNA from human faecal samples," J Microbiol Methods, vol. 50, no. 2, pp. 131-139, 2002.

[12] S. A. Miller, D. D. Dykes, and H. F. Polesky, "A simple salting out procedure for extracting DNA from human nucleated cells," Nucleic Acids Res, vol. 16, no. 3, pp. 12-15, 1988.

[13] E. Suenaga and H. Nakamura, "Evaluation of three methods for effective extraction of DNA from human hair," J Chromatogr B Analyt Technol Biomed Life Sci, vol. 820, no. 1, pp. 137-141, 2005.

[14] A.V. Tataurov, Y. You, and R. Owczarzy, "Predicting ultraviolet spectrum of single stranded and double stranded," Biophysical Chemistry, vol. 133, issue 1-3, pp. 66-70, March 2008.

[15] H. L. Katcher and I. Schwartz, "A distinctive property of Tth DNA polymerase: enzymatic amplification in the presence of phenol," Biotechniques, vol. 16, no. 1, pp. 84-92, 1994.

[16] M. Shioda and K. Murakami-Murofushi, "Selective inhibition of DNA polymerase alpha by a polysaccharide purified from slime of Physarum polycephalum," Biochem Biophys Res Commun, vol. 146, no. 1, pp. 61-66, 1987. 